\title{
Treatment of $\mathrm{Cu} / \mathrm{Zn}$ wastes by combined PSU- electrodeposition processes
}

\author{
Javier Llanos*, Manuel A. Rodrigo, Ángel Pérez, Pablo Cañizares \\ Chemical Engineering Department, University of Castilla-La Mancha, Edificio Enrique \\ Costa Novella. Campus Universitario s/n, 13005 Ciudad Real, Spain
}

\begin{abstract}
This work is focused on the study of the electrodeposition stage of a combined polymersupported ultrafiltration (PSU)-electrodeposition process for the recovery and selective separation of $\mathrm{Cu} / \mathrm{Zn}$ mixtures. With this aim, the electrodeposition of $\mathrm{Cu} / \mathrm{Zn}$ mixtures was evaluated in the presence of ethoxylated polyethylenimine, a polymer that has exhibited good performance in PSU processes in previous studies and whose performance has been fully characterised in the literature. It was determined that at $\mathrm{pH}$ values equal to or less than 4 , macromolecular complexes formed with both $\mathrm{Cu}$ and $\mathrm{Zn}$ are weak and electrodeposition can take place very efficiently, with the deposition of copper being strongly favoured. For values of the applied electrical charge equal or greater than $0.1 \mathrm{~A} \mathrm{~h} \mathrm{dm}^{-3}$, the purity of the copper deposit is greater than $99 \%$ for the range of $\mathrm{Cu} / \mathrm{Zn}$ molar ratios between 1 and infinity. Next, long-term experiments in continuous mode showed that the average deposition rate was close to the maximum rate achieved when operating in discontinuous mode and that the electrodeposition process does not negatively affect the performance of the polymer in the PSU processes.
\end{abstract}


Keywords: Electrodeposition, copper, selective separation, ultrafiltration, electrochemical regeneration.

*Corresponding author e-mail: javier.llanos@uclm.es. Tel.: +34-926-29-53-00 Ext. 3511; fax: +34-926-29-52-56 


\section{Introduction}

The presence of heavy metal ions in aqueous effluents represents at least two challenges. Due to their toxicity, it is imperative to remediate aqueous effluents containing heavy metal ions to prevent environmental degradation and human exposure. Moreover, the recovery and selective separation of multicomponent heavy metal ion mixtures may represent an economic opportunity because the price of pure metals has experienced a marked increase during the recent years (Llanos et al., 2010; Sgarlata et al., 2008).

Many techniques can be applied to recover and selectively separate heavy metal ions from multicomponent mixtures. Amongst them, membrane processes are regarded as highly effective, selective techniques for application in such separations. More specifically, polymer-supported ultrafiltration (PSU) has been applied to remove (Aliane et al., 2001; Geckeler and Volchek, 1996; Roach and Zapien, 2009; Uludag et al., 1997) and recover (Cañizares et al., 2008; Llanos et al., 2008; Zeng et al., 2012) a wide variety of heavy metal ions. Moreover, water-soluble polymers exhibit a different binding affinity towards different metal ions, so this technique has been widely applied to the selective separation of metal ion mixtures (Camarillo et al., 2010; Kadioglu et al., 2010; Rivas et al, 2004).

Another technology used to achieve the selective separation of heavy metal ions is electrodeposition (Chen, 2004; Pilla et al., 2000; Yang, 2003). The differences in the reduction potentials of different metal ions make possible to preferentially remove the ions that have higher positive reduction potential values. Moreover, electrodeposition can be used to recover the metal ion and regenerate the polymer that has been previously used in a PSU process (Barron-Zambrano et al., 2004; Llanos et al., 2009). 
Once the metal ion from concentrated solution from the PSU stage is electrodeposited, the polymer can be subsequently used in several more retention cycles.

Taking into account the characteristics of both techniques, it is possible to establish an integrated process of enhanced selectivity by using a first step with PSU and a second step with electrodeposition (graphical abstract). In previous studies, the selectivity of the PSU technique to separate $\mathrm{Cu} / \mathrm{Zn}$ mixtures was demonstrated by performing tests with two metal ions containing mixtures (Llanos et al., 2010). Moreover, the feasibility of the polymer regeneration and metal recovery with single metal ion (copper ion) containing solutions was evaluated in discontinuous mode (Llanos et al., 2009).

Thus, the goals of this work can be summarised into two key points. First, this work aims at testing the selectivity of the electrodeposition technique in the selective separation of $\mathrm{Cu} / \mathrm{Zn}$ mixtures and its ability to remove $\mathrm{Zn}^{2+}$ ions. These results, taken together with previously obtained data on the selective separation of these ions with the PSU technique, can be applied to the design of an integrated process PSUelectrodeposition of enhanced selectivity (as shown in the graphical abstract). Moreover, within the present work, experiments with monometallic $\mathrm{Cu}^{2+}$ solutions will be performed in continuous mode (this would be the firs step in a scale-up study). With these tests, the long-term performance of the polymer regeneration stage is evaluated.

\section{Material and methods}

\subsection{Analytical techniques}

The polymer used was $80 \%$ ethoxylated polyethylenimine ( $\mathrm{Mw} 50,000)$ in aqueous solution $(37 \% \mathrm{w} / \mathrm{w})$ supplied by Aldrich. The polymer concentration was measured with a total organic carbon (TOC) analyser Shimadzu 5050A. The metallic salts used 
were copper sulphate 5-hydrate and zinc sulphate 7-hydrate, both of analytical grade from Panreac. Ionic strength was fixed by adding sodium sulphate 10-hydrate of analytical grade from Panreac. Copper and zinc concentrations were measured with atomic absorption spectrophotometry (Varian, SpectrAA 220). All solutions were prepared with ultrapure water.

\subsection{Experimental setup}

The cell (schematically included as supplementary material) consists of a singlecompartment glass reactor (inner diameter $=105 \mathrm{~mm}$; height $=150 \mathrm{~mm}$; working volume: $0.6 \mathrm{~L}$ ) that operates in batch mode. The working electrode (cathode) is a rotating porous graphite with a square prism shape $($ side $=60 \mathrm{~mm}$; width $=10 \mathrm{~mm}$ ) from PocoFoam. It acts as the working electrode and as a stirrer simultaneously, and its main characteristics are presented as supplementary material. The working electrode stirring rate is set and measured by a Heidolph R7R 2021 stirrer. The counterelectrode (anode) is a cylindrical porous graphite electrode from Sofatel (inner diameter $=80 \mathrm{~mm}$; outer diameter $=100 \mathrm{~mm}$; height $=120 \mathrm{~mm}$ ). Its cylindrical shape was selected to assure a good distribution of current lines. The electrical current was applied using a Delta ES030-05 Power Supply, and the working electrode potential was measured vs. a $\mathrm{Ag} / \mathrm{AgCl}$ reference electrode using a Keithley 2000 Digital Multimeter.

\section{Results and discussion}

\section{1. $\mathrm{Cu}-\mathrm{Zn}$ selective separation.}

As it has been previously reported, the electrochemical regeneration method is not only a feasible way to perform polymer regeneration but it is also an alternative for designing 
a global PSU-electrodeposition process of enhanced selectivity, as both methods may present a high selectivity in the separation of heavy metal mixtures (Jüttner et al., 2000; Mayén-Mondragón, 2008; Molinari et al., 2007). To evaluate the performance of this technique, the influence of both the $\mathrm{pH}$ and $\mathrm{Cu} / \mathrm{Zn}$ ratio was studied.

\subsubsection{Influence of $\mathrm{pH}$ on $\mathrm{Cu}-\mathrm{Zn}$ separation in discontinuous mode.}

Among all process parameters, the $\mathrm{pH}$ most significantly affects the equilibria between ionic species in the system (Rivas et al., 2003). To evaluate the influence of this variable, discontinuous tests with equimolar $\mathrm{Cu} / \mathrm{Zn}$ solutions were performed at increasing $\mathrm{pH}$ values. Polymer and metal ion concentrations were fixed by maintaining the same total polymer/metal ion ratio, which was optimised in previous works (Llanos et al., 2008). Figs. 1 to 3 show the changes in the concentration and selectivity with the applied electrical charge at $\mathrm{pH}$ values ranging from 2 to 6 . In these figures, the value of the electrodeposition selectivity ( $\left.\alpha_{\mathrm{ED}}\right)$ is obtained according to Eq. (1), where $\left[\mathrm{Me}^{2+}\right]_{0}$ and $\left[\mathrm{Me}^{2+}\right]_{\mathrm{t}}$ are the $\mathrm{Me}^{2+}$ concentration initially and at time $t$, respectively.

$$
\alpha_{E D}=\frac{\left[\mathrm{Cu}^{2+}\right]_{0}-\left[\mathrm{Cu}^{2+}\right]_{t}}{\left[\mathrm{Zn}^{2+}\right]_{0}-\left[\mathrm{Zn}^{2+}\right]_{t}}
$$

The first observation that can be noticed from these figures is that copper deposition is clearly favoured with respect to zinc electrodeposition. This observation can be explained in terms of the differences in the reduction potential of both metal ions. As an indication, standard reduction potentials are $+0.12 \mathrm{~V}$ and $-0.98 \mathrm{~V}$ (vs. the $\mathrm{Ag} / \mathrm{AgCl}$ reference electrode) for $\mathrm{Cu}^{2+}$ and $\mathrm{Zn}^{2+}$ reduction, respectively, although the actual value will depend on the concentration, according to the well-known Nernst equation. This difference means that $\mathrm{Cu}^{2+}$ reduction to metallic copper is thermodynamically favoured 
compared to $\mathrm{Zn}^{2+}$ reduction. Although the better deposition of $\mathrm{Cu}^{2+}$ ions with respect to $\mathrm{Zn}^{2+}$ is not surprising, the fact that a high selectivity is maintained in the presence of the polymer at moderately acidic $\mathrm{pH}$ values $(\mathrm{pH}=4)$ represents one of the most important contributions of this work.

At $\mathrm{pH}$ 6, the copper electrodeposition rate diminishes, and the $\mathrm{Zn}^{2+}$ removal rate increases. This result causes a decrease in the electrodeposition selectivity by a factor of 100 , with respect to lower $\mathrm{pH}$ values. This behaviour can be explained on the basis of the equilibrium that is reached in the system: the polymer (L) can bind not only metal ions but also other cations as protons, and the complex formation constant of the selected polymer with $\mathrm{Cu}^{2+}$ ions is two orders of magnitude higher than with $\mathrm{Zn}^{2+}$ (Llanos et al., 2010). At pH values of 2 and 4, macromolecular complexes formed with both $\mathrm{Cu}^{2+}$ and $\mathrm{Zn}^{2+}$ are weakened, and electrodeposition can take place without mass transfer limitations. Conversely, at $\mathrm{pH}$, the macromolecular complex $\mathrm{L}_{-} \mathrm{Cu}^{2+}$ is stronger, so the mass transfer of $\mathrm{Cu}^{2+}$ free ions to the cathode surface, as well as their reduction on the cathode surface, are hindered.

The lower selectivity obtained at $\mathrm{pH} 6$ plays a negative role on the purity of the copper deposit, as is shown in Fig. 4, which shows the evolution of copper deposition and its purity with $\mathrm{pH}$ and the applied electrical charge.

The purity of the $\mathrm{Cu}$ deposit is close to $100 \%$ for $\mathrm{pH}$ values equal to or lower than 4 . This result is directly related to the high selectivity of $\mathrm{Cu}$ deposition over $\mathrm{Zn}$, and it implies that a selective separation of both metals can be performed within this range of $\mathrm{pH}$. In a previous study of selective separation with the PSU technique (Llanos et al., 2010), the maximum selectivity coefficient in the separation of $\mathrm{Cu}^{2+} / \mathrm{Zn}^{2+}$ bimetallic solutions was achieved at $\mathrm{pH} 4$ and 6 . These results imply that it is possible to design an integrated PSU-electrodeposition process of enhanced selectivity that would work at $\mathrm{pH}$ 
4 in both stages, without the need for changing the $\mathrm{pH}$ value between stages. This $\mathrm{pH}$ was selected to perform the remainder of the experiments in the present work.

Regarding electrodeposition, the only stage that should be tested to certify the technical viability of the technique is the final electrodeposition of $\mathrm{Zn}^{2+}$ once $\mathrm{Cu}^{2+}$ has been deposited (ED stage 2 of graphical abstract). To study (preliminarily) this stage, three electrodeposition tests with monometallic $\mathrm{Zn}^{2+}$ solutions were performed at increasing current densities, maintaining the same polymer concentration (Fig. 5). As shown in the figure, it is possible to perform the electrochemical deposition of $\mathrm{Zn}$ at a current density of $9.7 \mathrm{~mA} \mathrm{dm}^{-3}$ (per unit of volume of electrode), obtaining a solution that is almost free of $\mathrm{Zn}^{2+}$ ions. In this case, the efficiency of $\mathrm{Zn}^{2+}$ electrodeposition increases with current density. This result is related to the higher voltage required to perform the electrodeposition at higher current densities. Nevertheless, the average current efficiency $(24.1 \%)$ observed during the process at a current density of $9.7 \mathrm{~mA} \mathrm{dm}^{-3}$ is less than that observed for copper, due to the more negative reduction potential value for $\mathrm{Zn}$.

\subsubsection{Influence of $\mathrm{Cu} / \mathrm{Zn}$ ion ratio on $\mathrm{Cu}-\mathrm{Zn}$ separation.}

For an efficient metal recovery, the electrodeposition stage should be placed after a retention step in the PSU technique. In this process, the retentate stream from the PSU step will be the target of the electrodeposition stage. Because the $\mathrm{Cu}^{2+}$ rejection coefficient is clearly higher than that of $\mathrm{Zn}^{2+}$, the $\mathrm{Cu}^{2+}$ concentration of this retentate stream should be much higher than the $\mathrm{Zn}^{2+}$ concentration. For this reason, it is important to evaluate the influence of the $\mathrm{Cu} / \mathrm{Zn}$ ion ratio on the process performance by evaluating a range of molar ratios from 1 to infinity $\left(\mathrm{Cu}^{2+}\right.$ ion containing solution). 
Thus, Fig. 6 represents the changes in the copper purity with respect to the applied electrical charge for increasing $\mathrm{Cu} / \mathrm{Zn}$ ion ratios at a constant initial $\mathrm{pH}$ value of 4 .

As expected, when the $\mathrm{Cu}^{2+} / \mathrm{Zn}^{2+}$ ion ratio increases, the $\mathrm{Cu}$ purity slightly increases because the concentration of $\mathrm{Zn}^{2+}$ available in the reactor is lower and zinc deposition is further hindered. Nevertheless, for values of the applied electrical charge equal or higher than $0.1 \mathrm{~A} \mathrm{~h} \mathrm{dm}^{-3}$, the copper deposit purity is higher than $99 \%$ for the entire range of $\mathrm{Cu}^{2+} / \mathrm{Zn}^{2+}$ molar ratios. This result again proves the selectivity of the electrodeposition technique and the potential selectivity of a combined PSUelectrodeposition process.

\subsection{Tests at continuous mode.}

Apart from the selectivity of the process, another key point is its performance in a longterm operation and the possibility of using the process in continuous mode rather than operating it in batch, especially considering that electrodeposition is a technique in which the properties of working electrode are clearly affected by the continuous deposition of metals. Thus, it is important to evaluate the efficiency of the process while working in continuous mode. With this in mind, two sets of experiments were performed to study the influence of the working flow rate and the cumulative deposition of copper on the working electrode. We also evaluated the effect of the electrodeposition stage on the performance of the polymer in the PSU processes.

\subsubsection{Influence of influent flow-rate}

To study the influence of the working flow rate, four experiments were performed by feeding the system with a copper concentration of $500 \mathrm{ppm}$ and an ethoxylated polyethylenimine concentration of $0.24 \%$ (the feed polymer/metal ratio was maintained 
with respect to the experiments performed at discontinuous mode). Fig. 7 presents the changes in the copper ion concentration in the reactor outlet, $[\mathrm{Cu}]_{\text {out }}$, with the applied electrical charge. Moreover, the average copper deposition rate $\left(\mathrm{r}_{\mathrm{D}}, \mathrm{mg} \mathrm{Cu} \mathrm{min}^{-1}\right)$ is also shown as a function of the influent flow rate.

As expected, the final copper ion concentration in the reactor outlet decreases with increasing residence times (lower influent flow rates), taking into account the mass balance of this continuous reaction system. Moreover, the copper ion concentration profile is similar in all cases. The average copper deposition rate can be compared with the maximum rate achievable in discontinuous mode, which according to a previous work (Llanos et al., 2009) is equal to $2.87 \mathrm{mg} \mathrm{Cu} \mathrm{min}^{-1}$. Considering that the values obtained in continuous tests include the first transitory stage of lower efficiency, it can be concluded that the average deposition rate obtained is very close to the maximum rate achievable in discontinuous mode. Furthermore, the copper deposition rate does not depend on the influent flow rate because the differences obtained between the different tests are negligible.

These results imply that the system efficiency is close to the maximum theoretical achievable value, which means that current efficiencies are close to $90 \%$; this value is clearly higher than that in previous research on polymer regeneration in PSU processes (Barron-Zambrano et al., 2004; Baticle et al., 2000; Issabayeva et al., 2006). Moreover, this maximum efficiency can be maintained within a broad range of feed flow rates. Consequently, within a broad range of final copper ion concentrations, this characteristic increases the versatility of the system.

\subsubsection{Electrode stability}


Finally, the technical viability of the process in terms of its long-term performance was also evaluated. To perform this study, four cycles of 10 hours (in which the process was operated in continuous mode up to the steady state) were performed consecutively, without removing the copper previously deposited upon the electrode surface. In every cycle, the influent was a copper ion solution with a concentration of $500 \mathrm{ppm}$. After each operation cycle, the entire volume of the reactor was substituted by the initial solution $\left(500 \mathrm{ppm} \mathrm{Cu}^{2+}\right)$ to compare the electrode performance beginning from the same initial conditions. Fig. 8 shows the results of these experiments in terms of the concentration evolution in the reactor outlet and the $\mathrm{Cu}^{2+}$ removal rate, $\mathrm{r}_{\mathrm{D}}$.

The cumulative deposition of copper on the electrode surface does not negatively affect the rate of $\mathrm{Cu}^{2+}$ removal. Conversely, the deposition positively impacts the removal rate, as this rate increases for cycles 3 and 4 with respect to the two first cycles. This increase in the $\mathrm{Cu}^{2+}$ reduction rate is primarily due to the lower extent of the initial stage of lower efficiency in cycles 3 and 4 . These results correlate with the experiments in discontinuous mode (Llanos et al., 2009), in which it was observed that copper deposition on the electrode surface enhances the efficiency of the process.

Finally, it was necessary to determine if the electrodeposition process negatively impacts the ability of the polymer to bind $\mathrm{Cu}^{2+}$ ions in the PSU processes. With this aim, the optimal $\mathrm{Cu}^{2+}$ loading ratio of the polymer for a PSU process was calculated for the regenerated polymer, following the procedure described elsewhere (Llanos et al., 2008). This procedure consists of performing PSU tests in total recirculation mode with the same polymer concentration but with an increasing metal concentration. The optimal loading ratio was defined as the loading ratio (mg metal ion/mg polymer) that would not lead to copper rejection below 0.97 at 4 bar of transmembrane pressure. In that work, the $\mathrm{Cu}^{2+}$ loading ratio was determined to be $208 \mathrm{mg} \mathrm{Cu} / \mathrm{g}$ PEIPE for a fresh polymer 
solution. In the present work, the optimal loading ratio for $\mathrm{Cu}^{2+}$ retention was calculated as $198 \mathrm{Cu} / \mathrm{g}$ PEIPE for the polymer that was previously used in the long-term electrodeposition tests. This result means that the polymer does not suffer a severe deactivation process and that it can be used in several consecutive ultrafiltrationelectrodeposition processes.

\section{Conclusions}

From this work, the following conclusions can be drawn:

1) Electrodeposition with a rotating-electrode electrochemical cell can be efficiently used to carry out a selective $\mathrm{Cu} / \mathrm{Zn}$ separation process. If this technique is coupled to a previous PSU process, electrodeposition can be used for both polymer regeneration and metal ions selective separation.

2) The electrodeposition stage can be performed at $\mathrm{pH} 4$ (the optimum level for $\mathrm{Cu} / \mathrm{Zn}$ separation in a PSU process) without affecting system selectivity. This high selectivity is also maintained for increasing $\mathrm{Cu} / \mathrm{Zn}$ molar ionic ratios within the range of 1 to infinity. Moreover, it is possible to remove $\mathrm{Zn}^{2+}$ ions in a second electrodeposition stage, also at $\mathrm{pH} 4$.

3) The performance of the electrodeposition technique in the long-term operation is considered in the present work. It is possible to work within a broad range of influent flow rates and throughout successive cycles of copper deposition without negatively affecting the process efficiency. Moreover, the polymer is not negatively affected by the electrodeposition process, so it could be applied in several consecutive ultrafiltration-electrodeposition processes.

\section{Acknowledgements}


The authors acknowledge funding support from the National Spanish Ministry of Education and Science (Project CTM2010-18833).

\section{References}

Aliane, A., Bounatiro, N., Cherif, A. T., Akretche, D. E., 2001. Removal of chromium from aqueous solution by complexation - ultrafiltration using a water-soluble macroligand. Water Research 35(9), 2320-2326.

Barron-Zambrano, J., Laborie, S., Viers, P., Rakib, M., Durand, G., 2004. Mercury removal and recovery from aqueous solutions by coupled complexation-ultrafiltration and electrolysis. Journal of Membrane Science 229(1-2), 179-186.

Baticle, P., Kiefer, C., Lakhchaf, N., Leclerc, O., Persin, M., Sarrazin, J., 2000. Treatment of nickel containing industrial effluents with a hybrid process comprising of polymer complexation - ultrafiltration - electrolysis. Separation and Purification Technology 18(3), 195-207.

Camarillo, R., Llanos, J., García-Fernández, L., Pérez, A., Cañizares, P., 2010. Treatment of copper (II)-loaded aqueous nitrate solutions by polymer enhanced ultrafiltration and electrodeposition. Separation and Purification Technology 70(3), 320328.

Cañizares, P., Pérez, A, Llanos, J., Rubio, G., 2008. Preliminary design and optimisation of a PEUF process for Cr(VI) removal. Desalination 223(1-3), 229-237.

Chen, G., 2004. Electrochemical technologies in wastewater treatment. Separation and Purification Technology 38(1), 11-41.

Geckeler, K. E., Volchek, K., 1996. Removal of hazardous substances from water using ultrafiltration in conjunction with soluble polymers. Environmental Science and Technology 30(3), 725-733. 
Issabayeva, G., Aroua, M. K., Sulaiman, N. M., 2006. Electrodeposition of copper and lead on palm shell activated carbon in a flow-through electrolytic cell. Desalination 194(1-3), 192-201.

Juttner, K., Galla, U., Schmieder, H., 2000. Electrochemical approaches to environmental problems in the process industry. Electrochimica Acta 45(15-16), 25752594.

Kadioglu, S. I., Yilmaz, L., Aydogan, N., Ozbelge, H. O., 2010. Removal of heavy metals from multicomponent metal mixtures by polymer enhanced ultrafiltration: Effects of $\mathrm{pH}$, ionic strength and conformational changes in polymer structure. Separation Science and Technology 45(10), 1363-1373.

Llanos, J., Pérez, A., Cañizares, P., 2008. Copper recovery by polymer enhanced ultrafiltration (PEUF) and electrochemical regeneration. Journal of Membrane Science 323(1), 28-36.

Llanos, J., Pérez, A., Rodrigo, M. A., Cañizares, P. 2009. Electrochemical regeneration of partially ethoxylated polyethylenimine used in the polymer-supported ultrafiltration of copper. Journal of Hazardous Materials 168(1), 25-30.

Llanos, J., Camarillo, R., Pérez, A., Cañizares, P., 2010. Polymer supported ultrafiltration as a technique for selective heavy metal separation and complex formation constants prediction. Separation and Purification Technology 73(2), 126-134. Mayén-Mondragón, R., Ibanez, J. G., Vasquez, R. C., Baeza, A., Oropeza, M. T., 2008. Electrochemical recovery of cadmium from simulated waste nickel-cadmium battery solutions. Water, Air, and Soil Pollution 194(1-4), 45-55.

Molinari, R., Poerio, T., Argurio, P., 2007. Chemical and operational aspects in running the polymer assisted ultrafiltration for separation of copper(II)-citrate complexes from aqueous media. Journal of Membrane Science 295(1-2), 139-147. 
Pilla, A. S., Duarte, M. M. E., Mayer, C. E., 2000. Some aspects of removal of copper and cobalt from mixed ion dilute solutions. Journal of Applied Electrochemistry 30(7), 831-838.

Rivas, B. L., Pereira, E. D., Moreno-Villoslada, I., 2003. Water-soluble polymer-metal ion interactions. Progress in Polymer Science 28(2), 173-208.

Rivas, B. L., Schiappacasse, L. N., Pereira, U. E., Moreno-Villoslada, I., 2004. Interactions of polyelectrolytes bearing carboxylate and/or sulfonate groups with $\mathrm{Cu}(\mathrm{II})$ and Ni(II). Polymer 45(6), 1771-1775.

Roach, J. D., Zapien, J. H., 2009. Inorganic ligand-modified, colloid-enhanced ultrafiltration: A novel method for removing uranium from aqueous solution. Water Research 43(18), 4751-4759.

Sgarlata, C., Arena, G., Longo, E., Zhang, D., Yang, Y., Bartsch, R. A., 2008. Heavy metal separation with polymer inclusion membranes. Journal of Membrane Science 323(2), 444-451.

Uludag, Y., Ozbelge, H. O., Yilmaz, L., 1997. Removal of mercury from aqueous solutions via polymer-enhanced ultrafiltration. Journal of Membrane Science 129(1), 93-99.

Yang, C., 2003. Recovery of heavy metals from spent Ni-Cd batteries by a potentiostatic electrodeposition technique. Journal of Power Sources 115(2), 352-359.

Zeng, J., Li, S., Sun, X., Chen, X., 2012. Application of polyelectrolyte-enhanced ultrafiltration for rhenium recovery from aqueous solutions. Chemical Engineering and Technology 35(2), 387-392. 


\section{List of Figures}

Figure 1. Normalised metal concentration and selectivity for discontinuous electrodeposition of $\mathrm{Cu}^{2+} / \mathrm{Zn}^{2+}$ mixtures. $\left[\mathrm{Zn}^{2+}\right]_{0}=\left[\mathrm{Cu}^{2+}\right]_{0}=1.57 \mathrm{mM}$. Temperature 25 ${ }^{\circ} \mathrm{C}$; polymer concentration, $0.096 \% \mathrm{w} / \mathrm{w}$; current density, $4.2 \mathrm{~mA} \cdot \mathrm{dm}^{-3}$; stirring rate, 200 rpm; supporting media, $0.15 \mathrm{M} \mathrm{Na}_{2} \mathrm{SO}_{4}$ solution; initial $\mathrm{pH}, 2$.

Figure 2. Normalised metal ion concentration and selectivity for discontinuous electrodeposition of $\mathrm{Cu}^{2+} / \mathrm{Zn}^{2+}$ mixtures. $\left[\mathrm{Zn}^{2+}\right]_{0}=\left[\mathrm{Cu}^{2+}\right]_{0}=1.57 \mathrm{mM}$; Temperature 25 ${ }^{\circ} \mathrm{C}$; polymer concentration $0.096 \% \mathrm{w} / \mathrm{w}$; current density $4.2 \mathrm{~mA} \cdot \mathrm{dm}^{-3}$; stirring rate 200 rpm; supporting media $0.15 \mathrm{M} \mathrm{Na}_{2} \mathrm{SO}_{4}$ solution; initial $\mathrm{pH} 4$.

Figure 3. Normalised metal ion concentration and selectivity for discontinuous electrodeposition of $\mathrm{Cu}^{2+} / \mathrm{Zn}^{2+}$ mixtures. $\left[\mathrm{Zn}^{2+}\right]_{0}=\left[\mathrm{Cu}^{2+}\right]_{0}=1.57 \mathrm{mM}$; Temperature 25 ${ }^{\circ} \mathrm{C}$; polymer concentration $0.096 \% \mathrm{w} / \mathrm{w}$; current density $4.2 \mathrm{~mA} \cdot \mathrm{dm}^{-3}$; stirring rate 200 rpm; supporting media $0.15 \mathrm{M} \mathrm{Na}_{2} \mathrm{SO}_{4}$ solution; initial $\mathrm{pH} 6$.

Figure 4. Quantification of the copper mass that is deposited and purity of the copper deposit as a function of initial $\mathrm{pH}\left(\mathrm{pH}_{0}\right)$ and applied electrical charge. $\left[\mathrm{Zn}^{2+}\right]_{0}=\left[\mathrm{Cu}^{2+}\right]_{0}$ $=1.57 \mathrm{mM}$; Temperature $25{ }^{\circ} \mathrm{C}$; polymer concentration $0.096 \% \mathrm{w} / \mathrm{w}$; current density $4.2 \mathrm{~mA} \cdot \mathrm{dm}^{-3}$; stirring rate $200 \mathrm{rpm}$; supporting media $0.15 \mathrm{M} \mathrm{Na}_{2} \mathrm{SO}_{4}$ solution.

Figure 5. Influence of the current density on the normalised $\mathrm{Zn}^{2+}$ concentration for discontinuous electrodeposition of $\mathrm{Zn}^{2+}$ monometallic solutions. $\left[\mathrm{Zn}^{2+}\right]_{0}=1.57 \mathrm{mM}$; Temperature $25{ }^{\circ} \mathrm{C}$; polymer concentration $0.096 \% \mathrm{w} / \mathrm{w}$; current density $4.2 \mathrm{~mA} \cdot \mathrm{dm}^{-3}$; stirring rate $200 \mathrm{rpm}$; supporting media $0.15 \mathrm{M} \mathrm{Na}_{2} \mathrm{SO}_{4}$ solution; initial pH 4. 
Figure 6. Purity of the copper deposit as a function of the initial $\mathrm{Cu}^{2+} / \mathrm{Zn}^{2+}$ molar ionic ratio and applied electrical charge. $\mathrm{pH}_{0}=4$; Temperature $25^{\circ} \mathrm{C}$; polymer concentration $0.096 \% \mathrm{w} / \mathrm{w}$; current density $4.2 \mathrm{~mA} \cdot \mathrm{dm}^{-3}$; stirring rate $200 \mathrm{rpm}$; supporting media 0.15 $\mathrm{M} \mathrm{Na}_{2} \mathrm{SO}_{4}$ solution.

Figure 7. $\mathrm{Cu}^{2+}$ concentration in the reactor outlet, $[\mathrm{Cu}]_{\text {out }}$, with respect to the inlet flow rate and the applied electrical charge for tests in continuous mode for an increasing feed flow rate. $\mathrm{Cu}^{2+}$ deposition rate, $\mathrm{r}_{\mathrm{D}}$, with respect to the inlet flow rate is also included. Residence time is shown in brackets. $\mathrm{pH}_{0}=4$; Temperature $25{ }^{\circ} \mathrm{C}$; polymer concentration $0.24 \% \mathrm{w} / \mathrm{w}$; current density $4.2 \mathrm{~mA} \cdot \mathrm{dm}^{-3}$; stirring rate $200 \mathrm{rpm}$; supporting media $0.15 \mathrm{M} \mathrm{Na}_{2} \mathrm{SO}_{4}$ solution.

Figure 8. $\mathrm{Cu}^{2+}$ concentration in the reactor outlet, $[\mathrm{Cu}]_{\text {out }}$, for the successive cycles with respect to the accumulated applied electrical charge. The average $\mathrm{Cu}^{2+}$ deposition rate, $\mathrm{r}_{\mathrm{D}}$, is also included. $\mathrm{Q}_{0}=0.39 \mathrm{~L} \mathrm{~h}^{-1} ; \mathrm{pH}_{0}=4$; Temperature $25^{\circ} \mathrm{C}$; polymer concentration $0.24 \% \mathrm{w} / \mathrm{w}$; current density $4.2 \mathrm{~mA} \cdot \mathrm{dm}^{-3}$; stirring rate $200 \mathrm{rpm}$; supporting media $0.15 \mathrm{M} \mathrm{Na}_{2} \mathrm{SO}_{4}$ solution. 
$-18$ 

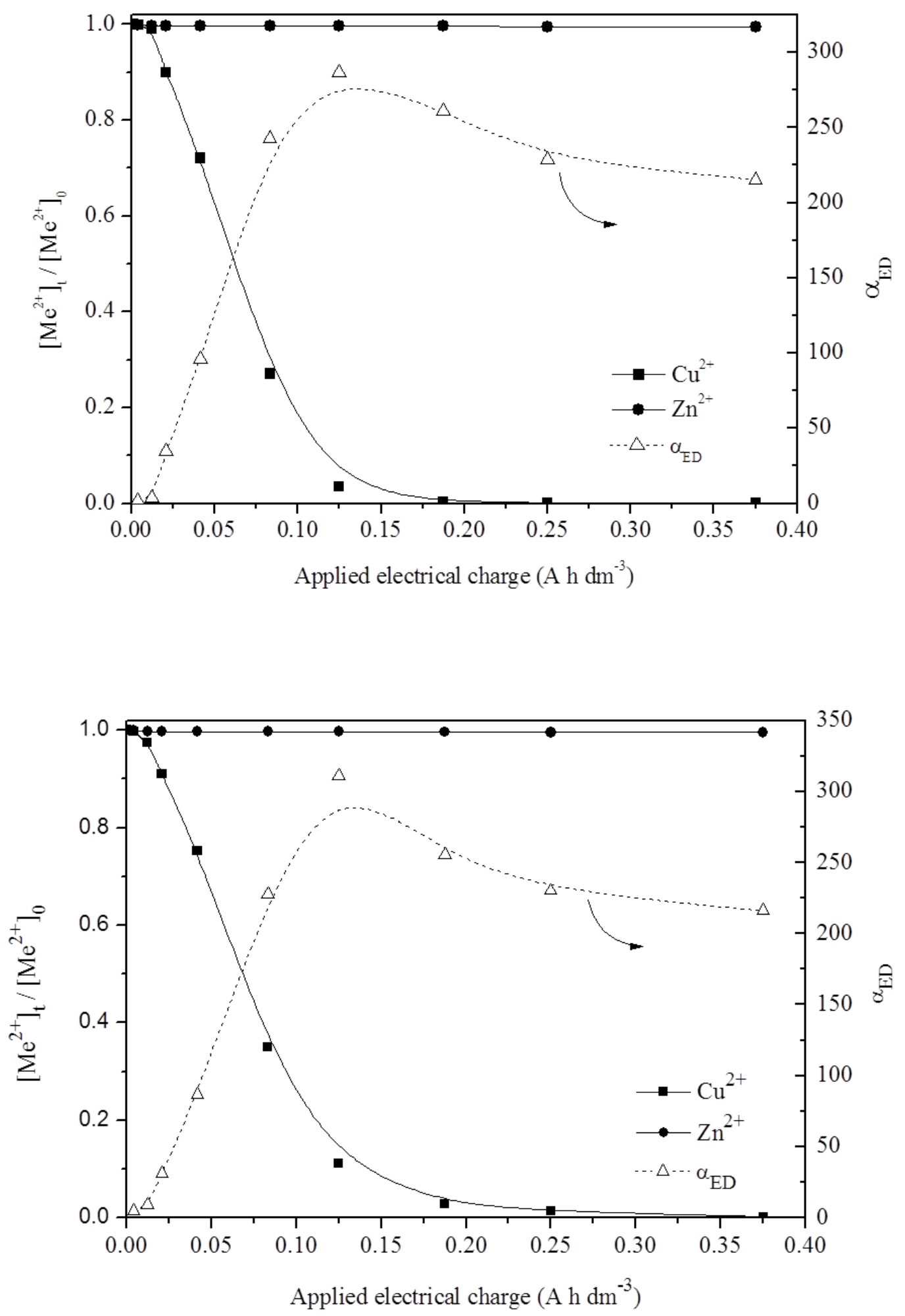

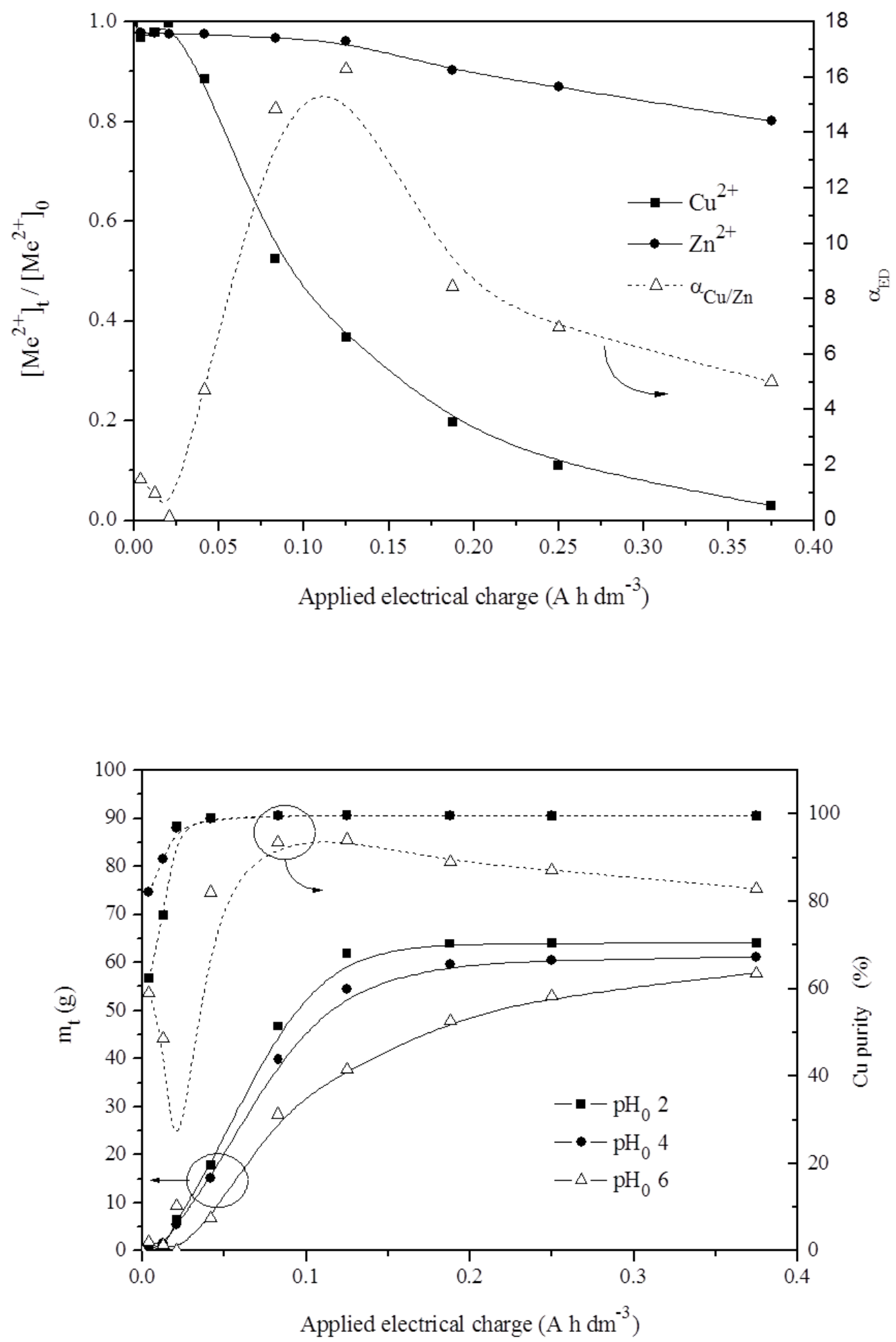

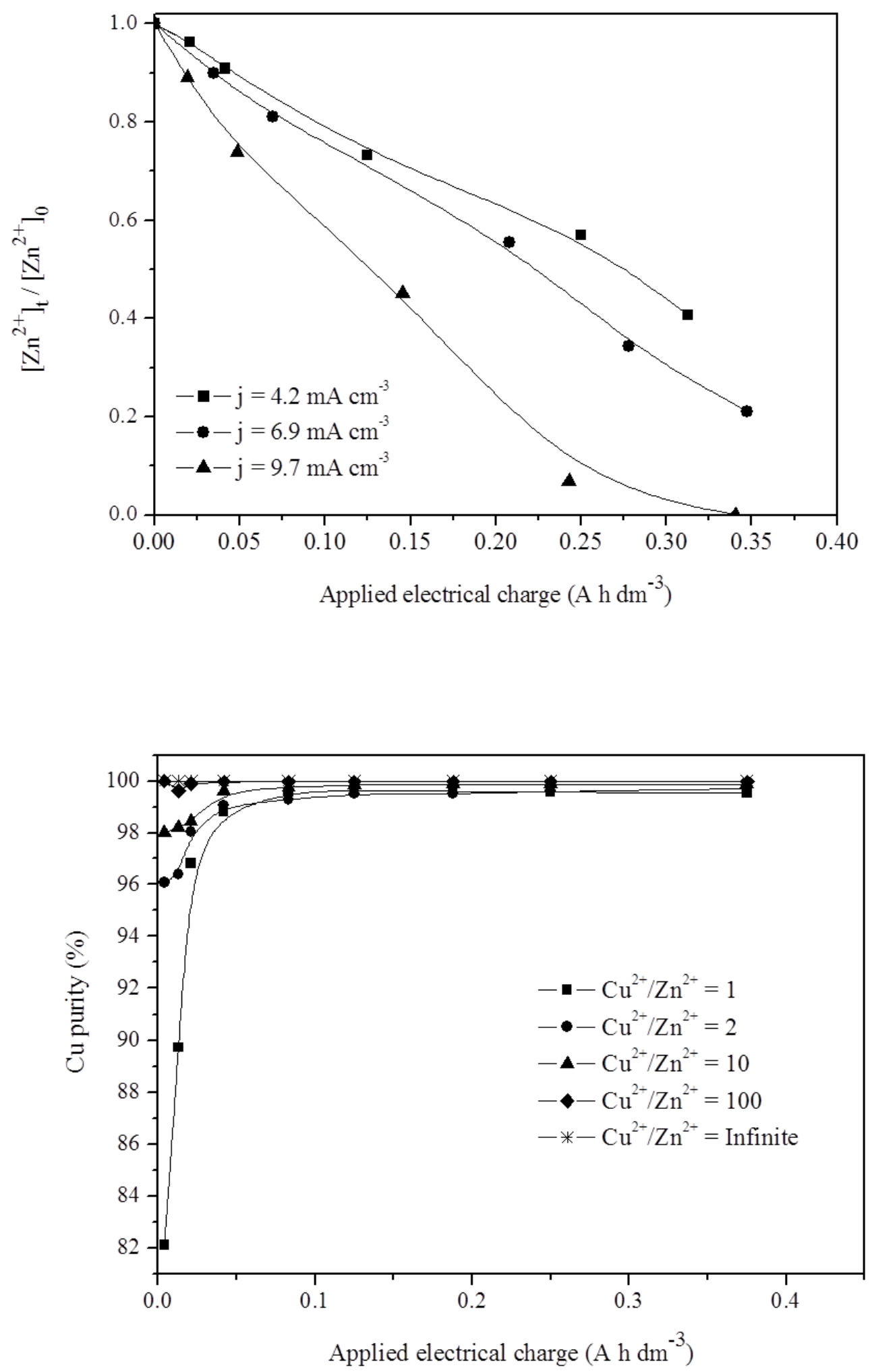

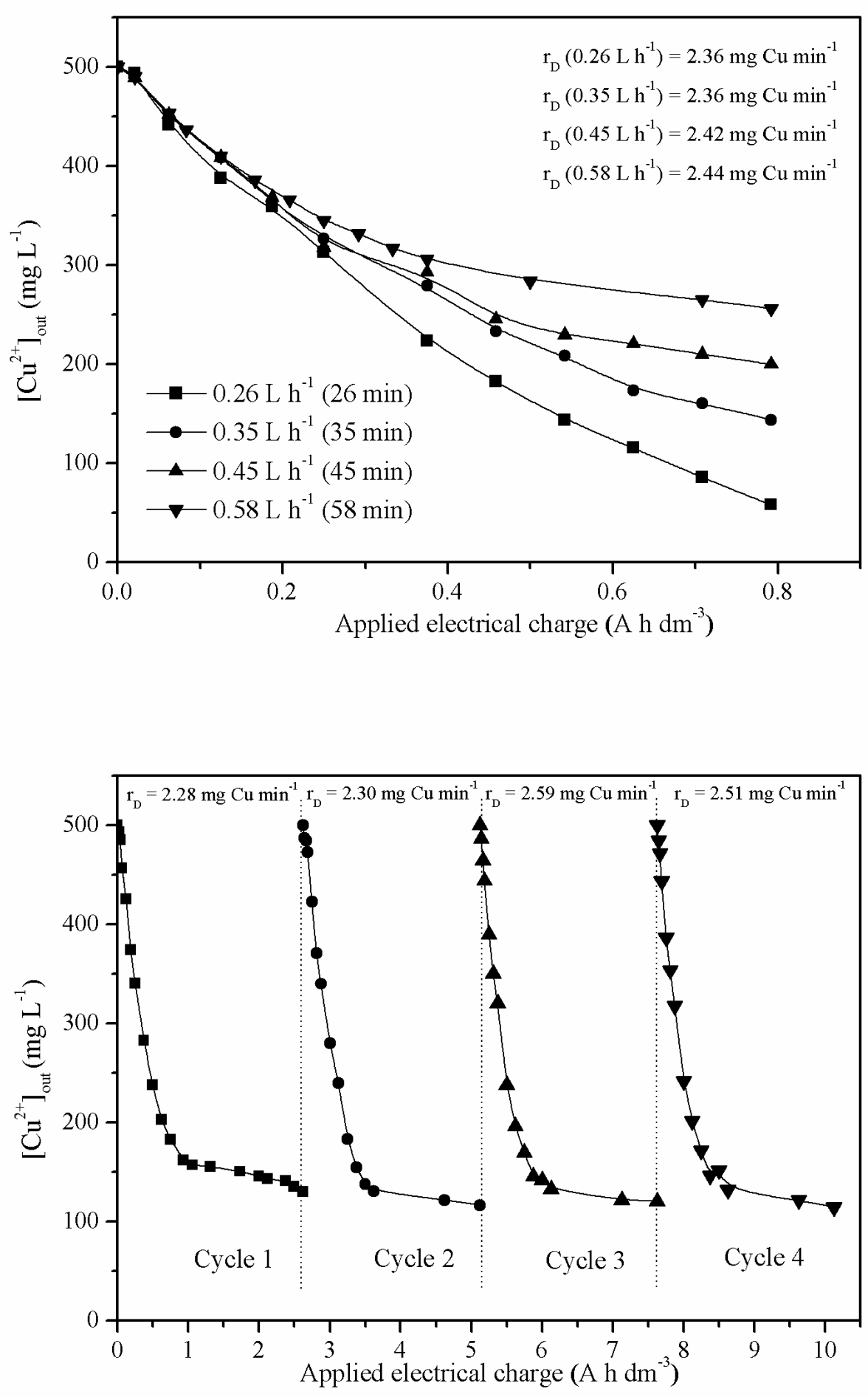


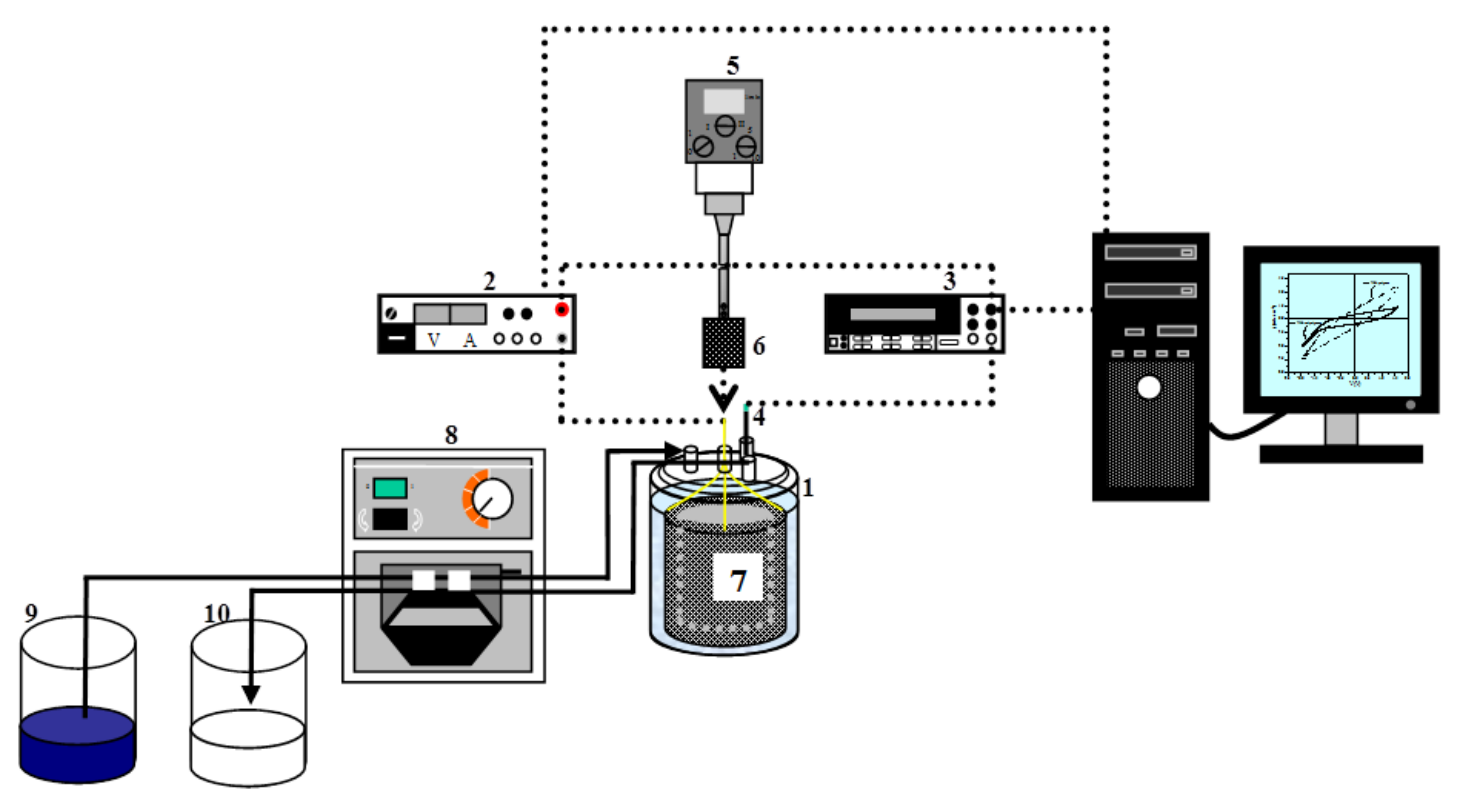

